\title{
FUZZY CONTROL OF SYNCHRONOUS MOTOR WITH PERMANENT MAGNET
}

\author{
Peter GIROVSKÝ \\ Department of Electrical Engineering and Mechatronics, Faculty of Electrical Engineering and Informatics, \\ Technical University of Košice, Letná 9, 04200 Košice, Slovak Republic, Tel.: +421 55602 2271, E-mail: peter.girovsky@tuke.sk
}

\begin{abstract}
In this paper we want to describe proposal of the fuzzy control of synchronous motor with permanent magnet and impact of deployment of membership functions of fuzzy controller on a regulation quality of a synchronous permanent magnet motor (PMSM). In the first part of this paper is described mathematical model of synchronous motor with permanent magnets and designed controller by using fuzzy logic. Fuzzy controller for a synchronous motor has been designed and compared for 3, 5 and 7 membership functions. Design and simulation of fuzzy control were done in Matlab/Simulink.
\end{abstract}

Keywords: synchronous motor, permanent magnet, fuzzy logic, controller

\section{INTRODUCTION}

Synchronous motor belongs to the AC electrical machines, which the importance, same as with asynchronous motors, is growing with the development of control and power semiconductor technology. The advantage of synchronous motors with permanent-magnet synchronous motor, compared with drive winding is the fact that due to the absence of drive winding excitation losses are eliminated and the need for a DC excitation current source and the possibility of failure drive winding. The advantages of the use of permanent magnets in the rotor as an exciter of the synchronous machine are mainly associated with the quality of the magnets themselves. Quality reflects the value of energy product of $(\mathrm{BH})_{\max }$ as an indicator of performance and resistance to demagnetization, heat resistance and the ratio of performance to price. The quality of the magnets themselves are in the process of developing synchronous motors with permanent magnets has increased significantly from AlNiCo, through ferrite magnets to those based on how NdBFe, SmCo.

Synchronous motor driven permanent magnet is characterized by high dynamics and precision. Thanks to compactness and low weight permanent magnets is possible to achieve a low moment of inertia and mentioned favourable dynamic properties. The disadvantage of synchronous motor with permanent magnets is its price, which affects the price of the materials from which they are made permanent magnets. The disadvantage is the high cost especially when seeking high specific torque.

Synchronous motors with permanent magnets can be divided into several groups according to the characteristics and parameters as follows:

By placing magnets on the rotor:

- motor with smooth rotor (non-salient poles)

- motor with salient poles (there are more ways of the magnets are located, which affects the characteristics of the motor)
By the shape of the rotor:

- long construction

- disk construction

By the shape of the course of the magnetic flux in the air gap:

- sinusoidal

- trapezoidal

A method of controlling synchronous drive is dependent on the desired properties of the motor, and is currently one of the most widespread vector control method which achieve maximum torque in static and dynamic modes of operation of the drive.

Vector control was originally designed for asynchronous motor [1], [2] and later was applied to the synchronous motor. Of the several methods of vector control for synchronous drives are the most widely used indirect current and voltage indirect vector control.

Using of fuzzy logic represent alternative solution to synchronous motor vector control. Control by the fuzzy logic is easier, faster and improves the control quality wherever we can describe the controller by the rules. Fuzzy logic is a method founded based on decision making rules. The advantage of using that method is mainly in its simplicity when creating models of complex nonlinear processes and use of experience and knowledge at design of control methods of these processes. Through the use of fuzzy logic, we can control a large part of the processes for which we do not know the exact mathematical description.

This work deals with the design of fuzzy control synchronous motor with permanent magnets in Matlab/Simulink and will be to serve for teaching and follow-up research work.

In the next part of the article is presented a mathematical model of the motor designed in Matlab / Simulink and fuzzy control of the motor. In the third part of the contribution is the comparison of the impact of membership functions for fuzzy controller on the controlled system. At the end of the paper is the simulation verification and evaluation of results achieved. 


\section{MATHEMATICAL MODEL OF SYNCHRONOUS MOTOR WITH PERMANENT MAGNETS IN D, Q COORDINATE SYSTEM}

The mathematical model of the synchronous motor with permanent magnets is described based on the known equations and describes behaviour of the machine in steady and transient states with respect on the following simplifying assumptions:

- motor parameters are constant, the same for all three phases

- the progress of magnetic induction in the air gap and the induced voltage is sinusoidal

- iron losses are neglected

- rotor damping winding and rotor material dampening effects are not considered

- ground wire is not connected

Equations for mathematical model is based on equivalent circuit of the synchronous motor with permanent magnets in rotor coordinates system $\mathrm{d}$, $\mathrm{q}$. Where $q$ represent torque axis and $d$ - represent magnetisation axis.

Differential equations (1) to (3) express the mathematical model of two-pole motor in the rotor coordinates [3]:

$\frac{d i_{1 d}}{d t}=\frac{1}{L_{s}} u_{1 d}-\frac{R_{s}}{L_{s}} i_{1 d}-\omega i_{1 q}$

$\frac{d i_{1 q}}{d t}=\frac{1}{L_{s}} u_{1 q}-\frac{R_{s}}{L_{s}} i_{1 q}+\omega i_{1 d}-\omega \frac{\psi_{m}}{L_{s}}$

$m=\frac{3 p}{2} \operatorname{Im}\left[\psi_{m}\left(i_{1 d}+j i_{1 q}\right)\right]$

To simplify of compiling a mathematical model constants are introduced:

$a_{1}=\frac{3 p^{2}}{2 J} \psi_{m} ; a_{2}=\frac{\psi_{m}}{L_{s}} ; a_{3}=\frac{R_{s}}{L_{s}}$

$b=\frac{1}{L_{s}} ; e=\frac{p}{J} ; \psi_{m}=\frac{2}{3 p} \frac{m}{i_{1 q}}$.



Fig. 1 Block diagram of synchronous motor with permanent magnates
Block diagram of synchronous motor with permanent magnets is shown on Fig. 1, where: $\boldsymbol{x}_{1}=\omega ; \boldsymbol{x}_{2}=i_{d} ; \boldsymbol{x}_{3}=$ $i_{q} ; \mathbf{z}=m_{z}$.

\section{FUZZY CONTROL OF SYNCHRONOUS MOTOR WITH PERMANENT MAGNETS}

For the design of control was used model for a synchronous motor with permanent magnets in a coordinate system $\mathrm{d}, \mathrm{q}$, which is described above in paper. We have designed regulated system with fuzzy PI controller, where by the FIS matrix are defined properties of the fuzzy controller. By the sampling period we can change the course of transient response of the fuzzy controller. The other way as we can change the response is the change of the gain at the input $(K e, K d e)$ and output $(K u)$. To limit the action value output we must to add saturation to the circuit. This saturation can slow us stabilize the controlled variable. But on the other hand, it prevents large oscillations controlled variable, which could damage the controlled system.

The basic method of management theory of regulation is control by the regulatory deviation. Let $w(t)$ is the required value of $y(t)$ is the output of the controlled process, and $u(t)$ is action value at the time t. For the dynamics capture of the regulator is needed following variables:

- Control error

- Change of error

$e(t)=w(t)-y(t)$

- Action value

$\Delta e(t)=e(t)-e(t-1)$

- Change of action value $\Delta u(t)=u(t)-u(t-1)$

Used control scheme with fuzzy controller is shown on Fig. 2.

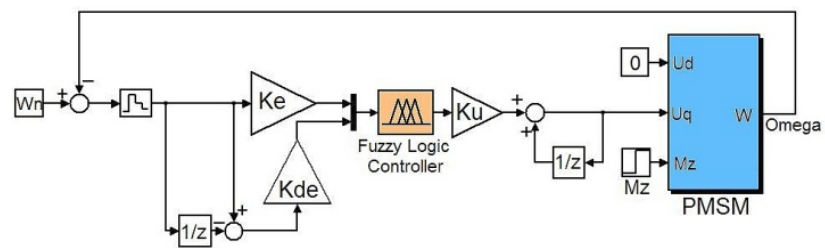

Fig. 2 Control loop of synchronous motor witch permanent magnets controlled by Fuzzy controller

As mentioned earlier, the sampling period we can change the course of transient response of the fuzzy controller and the other way as we can change the response is the change of the gain at the input $(\mathrm{Ke}, \mathrm{Kde})$ and output $(K u)$.

The sampling period was set to 0.01 . For the membership function was selected triangular shape and for the other functions was elected trapezoidal shape. To achieve the desired duration of controlled variable we set the gain at the input $e$, and the output $d u$ follows: $K e=1 /\left(\omega_{\mathrm{n}} * 2,7\right), K d e=1 /\left(\mathrm{w}_{\mathrm{n}} * 80\right), K d u=7,3$. hese settings provide the required course of controlled variable. Course of angular speed of synchronous motor witch permanent magnets controlled by fuzzy controller is shown in Fig. 3, where the setpoint angular velocity was $\omega_{\mathrm{n}}=104,72 \mathrm{rad} / \mathrm{s}$ and at the time $0.1 \mathrm{~s}$ was motor load. 


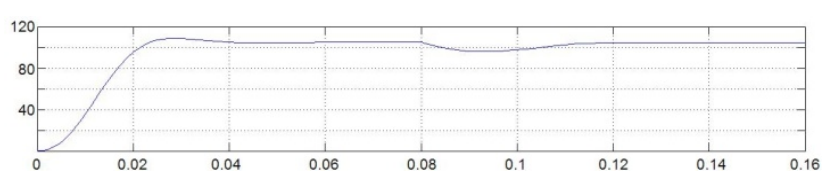

Fig. 3 Course of angular speed of synchronous motor witch permanent magnets controlled by fuzzy controller

4. INFLUENCE OF THE SHAPE AND LAYOUT OF MEMBERSHIP FUNCTIONS FOR THE FUZZY CONTROL OF SYNCHRONOUS MOTOR WITH PERMANENT MAGNETS

For testing, we selected three kinds of settings for configuration of membership functions of FIS matrixes:

- Setting 1: Symmetric configuration for all variables $e$, $d e$, and $d u$.

- Setting 2: Symmetrical configuration, with membership functions are compressed at around value 0 for all variables $e$, $d e$, and $d u$.

- Setting 3: Compression of membership functions of the input $e$ around value 0 and symmetrical configuration of membership functions for de and nonlinear configuration of membership functions on a output for $d u$.

\subsection{Influence of the shape and layout for 3 membership functions}

For individual variables $(e, d e$, and $d u$ ) for five membership functions, was used the following base of rules $-\{N, Z, P\}$.

Table 1 Base of rules for three membership functions

$\boldsymbol{e}$\begin{tabular}{|c|c|c|c|}
\multicolumn{5}{c}{$\boldsymbol{e}$} \\
\cline { 2 - 5 } & $\mathbf{N}$ & $\mathbf{Z}$ & $\mathbf{P}$ \\
\hline $\mathbf{N}$ & $\mathbf{N}$ & $\mathbf{N}$ & $\mathbf{Z}$ \\
\hline $\mathbf{Z}$ & $\mathbf{N}$ & $\mathrm{Z}$ & $\mathbf{P}$ \\
\hline $\mathbf{P}$ & $\mathrm{Z}$ & $\mathbf{P}$ & $\mathbf{P}$ \\
\hline
\end{tabular}

For the simulation we created three control systems with three PI fuzzy controllers. For the individual schemes have been allocated FIS matrix shown in Fig. 4. For individual gain on the input and output were used initial gain value which to provide the required course of controlled variable are described above.

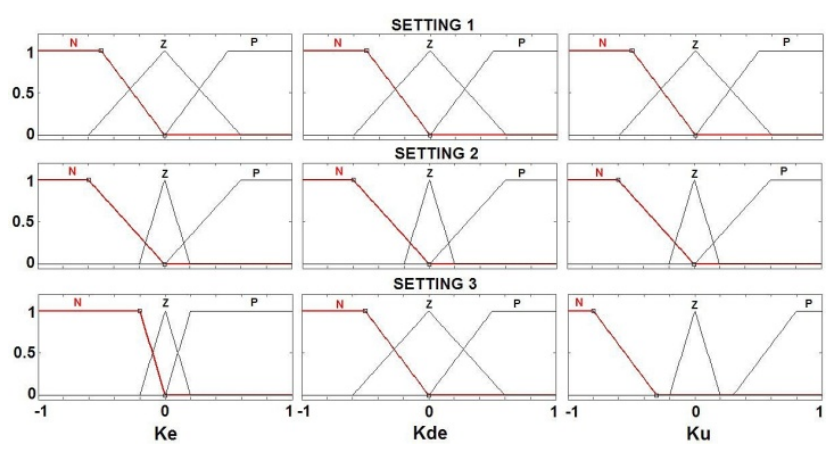

Fig. 4 FIS matrix for individual settings for three membership functions
Results of this simulation are shown on a Fig. 5. From the curves we can see, that settings of the first FIS matrix is good and change of the gain is not required. FIS matrix with setting 2 and 3 will cause oscillations of the controlled variable. By the change of gain for settings 2 and 3, we eliminate oscillations of controlled variable and the result, then near the required course.

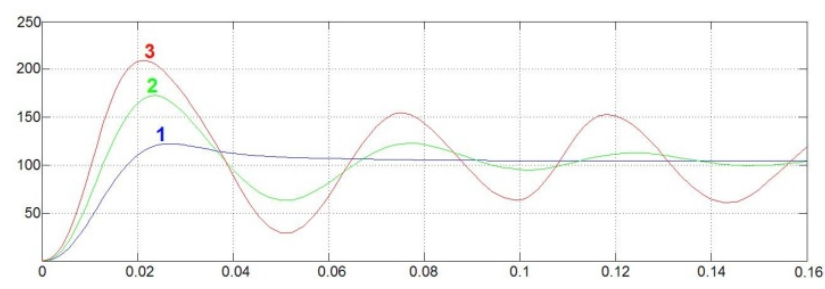

Fig. 5 Curves of controlled variable for 3 membership functions

\subsection{Influence of the shape and layout for 5 membership functions}

For individual variables $(e, d e$, and $d u$ ) for five membership functions, was used the following base of rules - $\{N B, N M, Z E, P M, P B\}$.

Table 2 Base of rules for three membership functions

\begin{tabular}{|c|c|c|c|c|c|}
\hline & NB & NM & $7 F$ & PM & PR \\
\hline NB & $\mathrm{NB}$ & NB & NM & $\mathrm{NM}$ & $\mathrm{ZE}$ \\
\hline NM & NB & NM & NM & $\mathbf{Z E}$ & $\mathbf{P M}$ \\
\hline $\mathbf{Z E}$ & NM & NM & $\mathbf{Z E}$ & $\mathbf{P M}$ & $\mathbf{P M}$ \\
\hline PM & NM & $\mathrm{ZE}$ & $\mathbf{P M}$ & PM & PB \\
\hline PB & $\mathrm{ZE}$ & $\mathbf{P M}$ & $\mathbf{P M}$ & PB & PB \\
\hline
\end{tabular}

As in the previous case for the simulation we created three control systems with three PI fuzzy controllers. For the individual schemes have been allocated FIS matrix shown in Fig. 6. For individual gain on the input and output were used initial gain value which to provide the required course of controlled variable are described above.

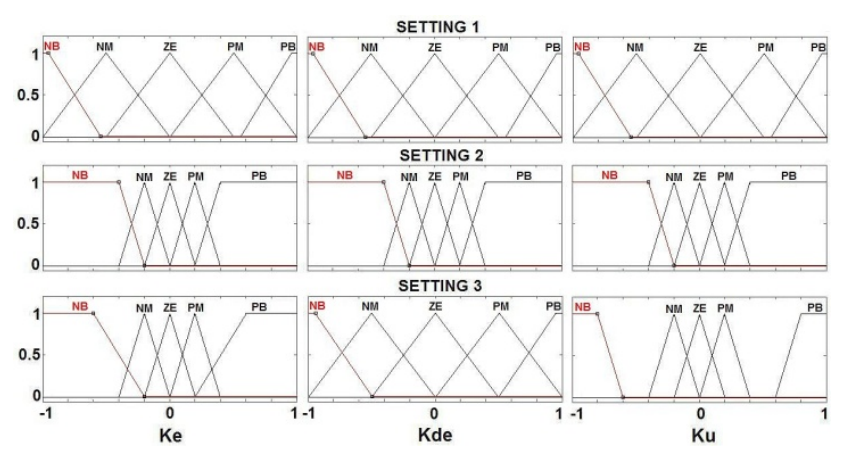

Fig. 6 FIS matrix for individual settings for five membership functions

The results of this simulation are shown in Fig. 7, from the curve we can see that changing the settings of membership functions caused the less change in the 
process variable, unlike the previous case with three membership functions in which the changes were more pronounced.



Fig. 7 Curves of controlled variable for 5 membership functions

\subsection{Influence of the shape and layout for 7 membership functions}

For individual variables $(e, d e$, and $d u$ ) for seven membership functions, was used the following base of rules - $\{N B, N M, N S, Z E, P S, P M, P B\}$.

Table 3 Base of rules for seven membership functions

\begin{tabular}{|c|c|c|c|c|c|c|c|}
\multicolumn{1}{|c}{ de } \\
\hline & NB & NM & NS & ZE & PS & PM & PB \\
\hline NB & NB & NB & NM & NM & NS & NS & ZE \\
\hline NM & NB & NM & NM & NS & NS & ZE & PS \\
\hline NS & NM & NM & NS & NS & ZE & PS & PS \\
\hline ZE & NM & NS & NS & ZE & PS & PS & PM \\
\hline PS & NS & NS & ZE & PS & PS & PM & PM \\
\hline PM & NS & ZE & PS & PS & PM & PM & PB \\
\hline PB & ZE & PS & PS & PM & PM & PB & PB \\
\hline
\end{tabular}

As in the two previous cases for the simulation we created three control systems with three PI fuzzy controllers. For the individual schemes have been allocated FIS matrix shown in Fig. 8. For individual gain on the input and output were used initial gain value which to provide the required course of controlled variable are described above.


Fig. 8 FIS matrix for individual settings for seven membership functions

The results of this simulation are shown in Fig. 9, from the curve we can see that changing the settings of membership functions caused the least change in the process variable, unlike the two previous cases in which the changes were more pronounced.

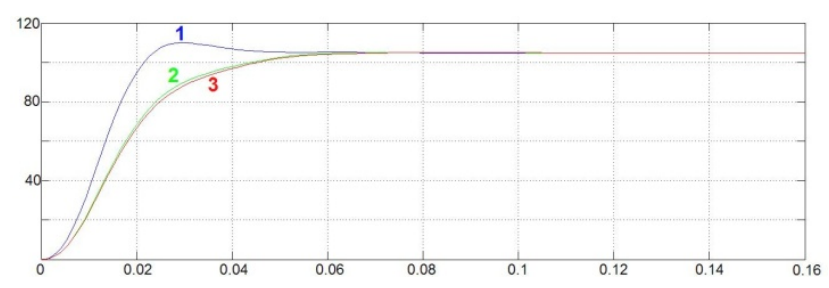

Fig. 9 Curves of controlled variable for 7 membership functions

\section{CONCLUSIONS}

The main objective of this study was to investigate impact of the change the deployment of fuzzy membership functions on a course of controlled variable of synchronous motor with permanent magnets. For determine of those effects was proposed controller for synchronous motor with permanent magnets on a based fuzzy logic and tested effect of modification fuzzy functions.

We have created various FIS matrix with three, five and seven membership functions and with three different settings. In testing FIS matrices showed that most preferably are defined by membership functions of the first set for 3, 5 and 7 of membership functions. Overall, however, the best course of controlled variable we achieved for the first FIS matrix settings for 7 membership functions.

\section{REFERENCES}

[1] BLASCHKE, F.: The principle of field orientation as applied to the new "transvector" closed-loop control system for rotating-field machines, Siemens Review, 39 (1972), 217-220.

[2] HASSE, K.: Zur dynamik drehzahlgeregelter antriebe mit stromrichtergespeisten asynchronkurschlusslaüfer maschinen. Techn. Hochsch., Darmstadt. Dissertation, (1969) 74-78.

[3] ZBORAY, L. - ĎUROVSKÝ, F. - TOMKO, J.: Controlled drives, Vienala, 2000.

[4] BRANDŠTETTER, P.: Alternating current controlled motors: Modern control methods, VŠB TU, Ostrava, 1999.

[5] NOVÁK, V.: Basics of Fuzzy modelling, 175 p., ISBN 80-7300-009-1, 2000 Praha, Ben.

[6] MǍ̌íK, V. - ŠTEPÁNKOVÁ, O. - LAŽANSKÝ, J.: Artificial intelligence, ISBN 80-200-1044-0, 2003, Praha, Academia.

\section{ACKNOWLEDGMENTS}

The authors wish to thank the project VEGA $1 / 0464 / 15$ for its support.

Received June 1, 2016, accepted October 6, 2016

\section{BIOGRAPHY}

Peter Girovský was born on 1979. In 2009 he graduated at the Department of Electrical Drives and Mechatronics of the Faculty of Electrical Engineering and Informatics at Technical University of Košice. His research interests include artificial intelligence, control systems, robotics. 